\title{
Selective reduction of organic compounds with aluminum and boron hydrides
}

\author{
Nung Min Yoon \\ Department of Chemistry, Sogang University \\ Seoul 121-742, Korea
}

\begin{abstract}
Several new selective reductions of organic compounds using complex metal hydrides and hydride reducing systems are discussed. Sodium diethylpiperidinoaluminate is an excellent agent for the partial reduction of esters to the corresponding aldehydes. Borohydride exchange resin (BER) is a convenient reagent for the chemoselective reduction of carbonyl compounds and also for reductive amination. $\mathrm{BER}-\mathrm{Ni}_{2} \mathrm{~B}$ has proved to be an excellent chemoselective reducing agent for olefins, halides, azides, and nitro compounds in the presence of many functional groups such as epoxides, esters, amides, and nitriles. On the other hand, BER-Cu is a reagent of choice for the reduction of $\alpha, \beta$-unsaturated acid derivatives and amine $\mathrm{N}$-oxides.
\end{abstract}

The discovery of sodium borohydride ${ }^{1}$ in 1942 and of lithium aluminum hydride ${ }^{2}$ in 1945 brought about a revolutionary change in procedures utilized for the reduction of functional groups in organic molecules. However, $\mathrm{NaBH}_{4}$ is a very mild reducing agent which reduces only aldehydes, ketones, and acyl chlorides, whereas $\mathrm{LiAlH}_{4}$ is an exceedingly powerful reducing agent, capable of reducing practically all organic functional groups. ${ }^{3}$ In order to find more selective reducing agents, considerable efforts have been made to modify these two extremes for more than forty years. ${ }^{4}$ Many new metal hydrides have been prepared, studies of the reducing characteristics of these hydrides have developed a number of selective reduction methods valuable to organic synthesis. Among them, several recent developments in our laboratory are discussed in this conference.

\section{Sodium Diethylpiperidinohydroaluminate (SDPA) ${ }^{5}$}

Since many selective metal hydride reducing agents, such as diisobutylaluminum hydride (DIBAH), ${ }^{6}$ lithium triethoxyaluminum hydride (LTEAH), ${ }^{7}$ and lithium tri-s-butylborohydride (L-Selectride), ${ }^{8}$ contain only one available hydride, it was of interest to us to prepare such a hydride. We prepared SDPA by reacting sodium diethyldihydroaluminate with one eq of piperidine. SDPA has been proved to be an excellent reagent for the partial reduction of carboxylic acid esters, amides, and nitriles to their corresponding aldehydes. ${ }^{9}$ Among these, the partial reduction of amides and nitriles can also be carried out by using LTEAH $^{7}$ and DIBAH. ${ }^{10}$ However, the partial reduction of esters is possible only with DIBAH at a very low temperature $\left(-78^{\circ} \mathrm{C}\right) .{ }^{11}$ In contrast to DIBAH, SDPA reduces carboxylic acid esters at $0^{\circ} \mathrm{C}$ in almost quantitative yields.

The mechanism of this partial reduction was studied: The reaction intermediate (A) of esters and SDPA rapidly rearranges through the migration of the piperidine group to $(\mathbf{B})$ which is stable under the reaction conditions and gives the corresponding aldehydes on hydrolysis (1). One limitation of SDPA is that it is

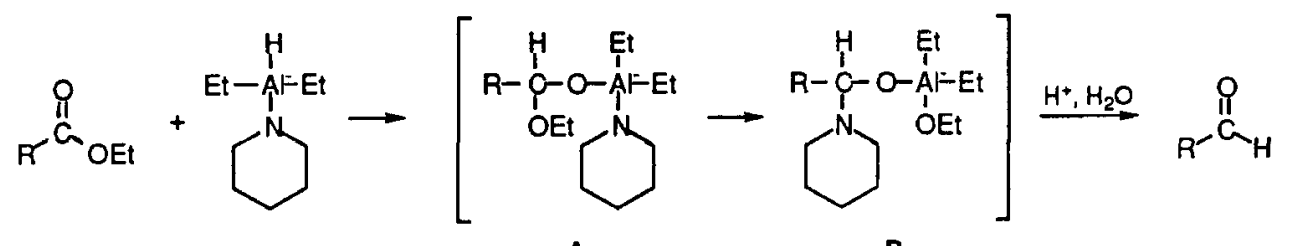


a strong base and causes extensive enolization in the reaction with aldehydes and ketones which have active $\alpha$-hydrogen. Somewhat lower yields of aliphatic aldehydes from aliphatic esters which have $\alpha$-hydrogen are due to this enolization. These lower yield were improved by using sodium diethyldihexylaminohydroaluminate. ${ }^{12}$ This study also led us to develop a good amidating agent of esters, sodium diethyldiamidoaluminate. ${ }^{13}$

\section{Alkyl Borohydrides}

In the borohydride area, we studied several alkyl borohydrides, such as $\mathrm{Li} 9-\mathrm{BBNH},{ }^{14} \mathrm{KEt}_{3} \mathrm{BH},{ }^{15} \mathrm{Ks}-$ $\mathrm{Bu}_{3} \mathrm{BH},{ }^{16} \mathrm{KPh}_{3} \mathrm{BH},{ }^{17}$ and developed some useful selective reductions. Esters were reduced selectively in the presence of carboxylic acids and halides with $\mathrm{Li}$ 9-BBNH and in the presence of epoxides and nitriles with $\mathrm{KEt}_{3} \mathrm{BH}$. Ks-Bu, $\mathrm{BH}$ reduced lactones without affecting esters. On the other hand, $\mathrm{KPh}_{3} \mathrm{BH}$ exhibited an excellent stereoselectivity in ketone reductions and a unique regioselectivity in the reduction of epoxides.

\section{Borohydride Exchange Resin (BER)}

From sometime ago, polymer supported borohydride has been prepared and utilized for eliminating a small amount of aldehydes or heavy metal salts. ${ }^{18} \mathrm{We}$ were interested in the use of borohydride exchange resin (BER) in the laboratory and found that BER is a more convenient reducing agent than sodium borohydride itself. It reduces aldehydes selectively in the presence of ketones (2) and reduces carbonyl compounds selectively without affecting ester, amide, nitrile, carbon-carbon multiple bond, or sulfoxide functionalities (3). Moreover, since boron moieties stay on the resin, a simple filtration of resin gives essentially pure products in most cases. ${ }^{19}$ BER is a quaternary ammonium borohydride supported on an ion exchange resin, Amberlite IRA-400, and is much more stable in alcoholic solvents than sodium borohydride. Therefore, it was possible to develop another application of BER, the reductive amination of carbonyl compounds ( $4 \& 5$ ), utilizing a rather slow decomposition of BER in weak acidic conditions. ${ }^{20}$<smiles>O=Cc1ccccc1</smiles><smiles>CC(=O)c1ccccc1</smiles>

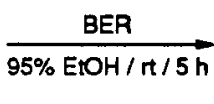<smiles>[OH2+]Cc1ccccc1</smiles>

$99 \%$<smiles>CC(O)c1ccccc1</smiles>

$1 \%$<smiles>CCOC(=O)C1CCCCC1=O</smiles>
$\frac{\mathrm{BER} / \mathrm{LICl}}{95 \% \mathrm{EtOH} / \mathrm{rt} / 3 \mathrm{~h}}$<smiles>CCOC(=O)C1CCCCC1O</smiles>
$92 \%$<smiles>CCCCCC=O</smiles><smiles>NC1CCCCC1</smiles>

$\frac{\mathrm{BER} / \mathrm{Et}_{3} \mathrm{NHCl}}{95 \% \mathrm{EtOH} / \mathrm{rt} / 1 \mathrm{~h}}$<smiles>CCCCCCNC1CCCCC1</smiles><smiles>CCCCCC(C)=O</smiles><smiles>NCc1ccccc1</smiles>
$\frac{\mathrm{BER} / \mathrm{Et}_{3} \mathrm{NHCl}}{95 \% \mathrm{EHOH} / \mathrm{rt} / 1 \mathrm{~h}}$<smiles>CCCCCCNCc1ccccc1</smiles>

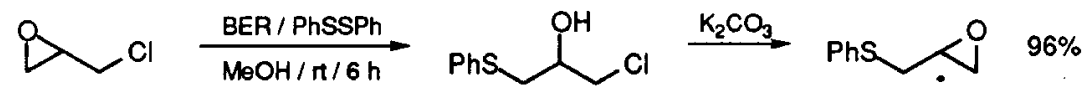


Thus BER is a good alternative reagent for $\mathrm{NaBH}_{3} \mathrm{CN}^{21}$ and pyridine borane ${ }^{22}$. Although BER is a weak hydride and reasonably stable in alcoholic solvents, it readily reduces diphenyl disulfide; and the resulting thiophenoxyborohydride is proved to be a convenient selective reagent for the synthesis of phenyl sulfides $(6 \& 7)^{23}$

\section{BER-Transition Metal Salts System}

Although $\mathrm{NaBH}_{4}$ is a very mild reducing agent, its reducing power is greatly enhanced in the presence of transition metal salts, and many reducing systems such as $\mathrm{NaBH}_{4}-\mathrm{NiCl}_{2}, \mathrm{NaBH}_{4}-\mathrm{CoCl}_{2}$, and $\mathrm{NaBH}_{4}-\mathrm{CuCl}_{2}$ have been applied to the reduction of various organic compounds. ${ }^{24}$ However, in the presence of these transition metal salts, $\mathrm{NaBH}_{4}$ rapidly decomposes in alcoholic solvents. Therefore, it has been the general practice to add solid $\mathrm{NaBH}_{4}$ portionwise to the mixture of the substrate and the transition metal salts. The procedures are greatly improved by using BER instead of $\mathrm{NaBH}_{4}$. Thus most reductions utilizing BER-transition metal salts proceeded quantitatively, and the products were isolated conveniently.

\section{1) BER-Ni ${ }_{2} \mathrm{~B}$ in Methanol}

A. Selective Reduction of Olefins: The selective hydrogenation of olefins is important in organic synthesis and is usually carried out by catalytic hydrogenation. Among the catalysts reported, Brown's P-2 nickel ${ }^{25}$ and Caubere's nickel complex reducing agent (NiCRA) ${ }^{26}$ have shown very good selectivity in the hydrogenation of olefins. The selectivity is usually more than $95 \%$. However, a small amount of substrates and/or rearranged olefins are contaminated in the products, and these are usually difficult to separate from the main product. We have found that $\mathrm{BER}-\mathrm{Ni}_{2} \mathrm{~B}$ in methanol exhibits complete selectivity among the structurally different olefins. Thus, monosubstituted olefins and norbornene were hydrogenated at $0^{\circ} \mathrm{C}$ in the presence of disubstituted olefins and trisubstituted olefins of $\alpha, \beta$-unsaturated esters, which in turn hydrogenated at $65^{\circ} \mathrm{C}$ without affecting trisubstituted olefins $(8 \& 9) .{ }^{27}$

B. Selective Reduction of Halides: Although the reduction of alkyl halides is easily carried out by $\mathrm{LiAlH}_{4}{ }^{27}$ and $\mathrm{LiEt}_{3} \mathrm{BH},{ }^{29}$ it was found that $\mathrm{NaBH}_{4}$ and $\mathrm{NaBH}_{3} \mathrm{CN}$ in polar aprotic solvents have advantages over these strong hydrides in that they display greater selectivity towards other reducible groups in the same molecule. ${ }^{30} \mathrm{We}$ found that $\mathrm{BER}-\mathrm{Ni}_{2} \mathrm{~B}$ in methanol is an excellent selective reducing agent both for aliphatic and aromatic halides. Primary bromides and iodides were quantitatively reduced in $3 \mathrm{~h}$ at room temperature using BER ( $5 \mathrm{eq})$ and $\mathrm{Ni}(\mathrm{OAc})_{2}(0.1 \mathrm{eq})$. However, cyclohexyl bromide (10) and cyclohexyl iodide were reduced at almost same rate; and even a tertiary bromide, 3-bromo-3-methylpentane, was reduced quantitatively in $3 \mathrm{~h}$ by using an increased amount of BER and $\mathrm{Ni}(\mathrm{OAc})_{2} \cdot{ }^{31}$ This is remarkable since in a typical $\mathrm{S}_{\mathrm{N}} 2$ reduction with $\mathrm{LiAlH}_{4}$, only $16 \%$ of cyclohexy bromide is reduced in $24 \mathrm{~h}^{28}$ 4-Bromo-1-chlorobutane was selectively reduced to 1-chlorobutane in a $95 \%$ yield. On the other hand, aromatic halides were reduced quantitatively in the presence of many other functional groups, such as hydroxymethyl, phenol, ester, cyano, and amino groups $(11) .^{32}$

C. Reduction of Azides: Since many azides can be prepared with good regio- and stereocontrol, and since a subsequent reduction permits a controlled introduction of an amino function, the reduction of azides to amines is important in organic synthesis. Primary, secondary, and tertiary azides are all reduced quantitatively in $1 \mathrm{~h}$ at room temperature (12) ${ }^{33}$ A one-pot synthesis of octylamine from octyl bromide is also possible without separating octyl azide (13). 
D. Reduction of Nitro Compounds: Primary, secondary, and tertiary aliphatic nitro compounds and aromatic nitro compounds are all reduced readily at room temperature. Halo and cyano substituents are simultaneously reduced at room temperature; but at $0{ }^{\circ} \mathrm{C}$, excellent selective reductions are realized $(14-16) .^{34}$

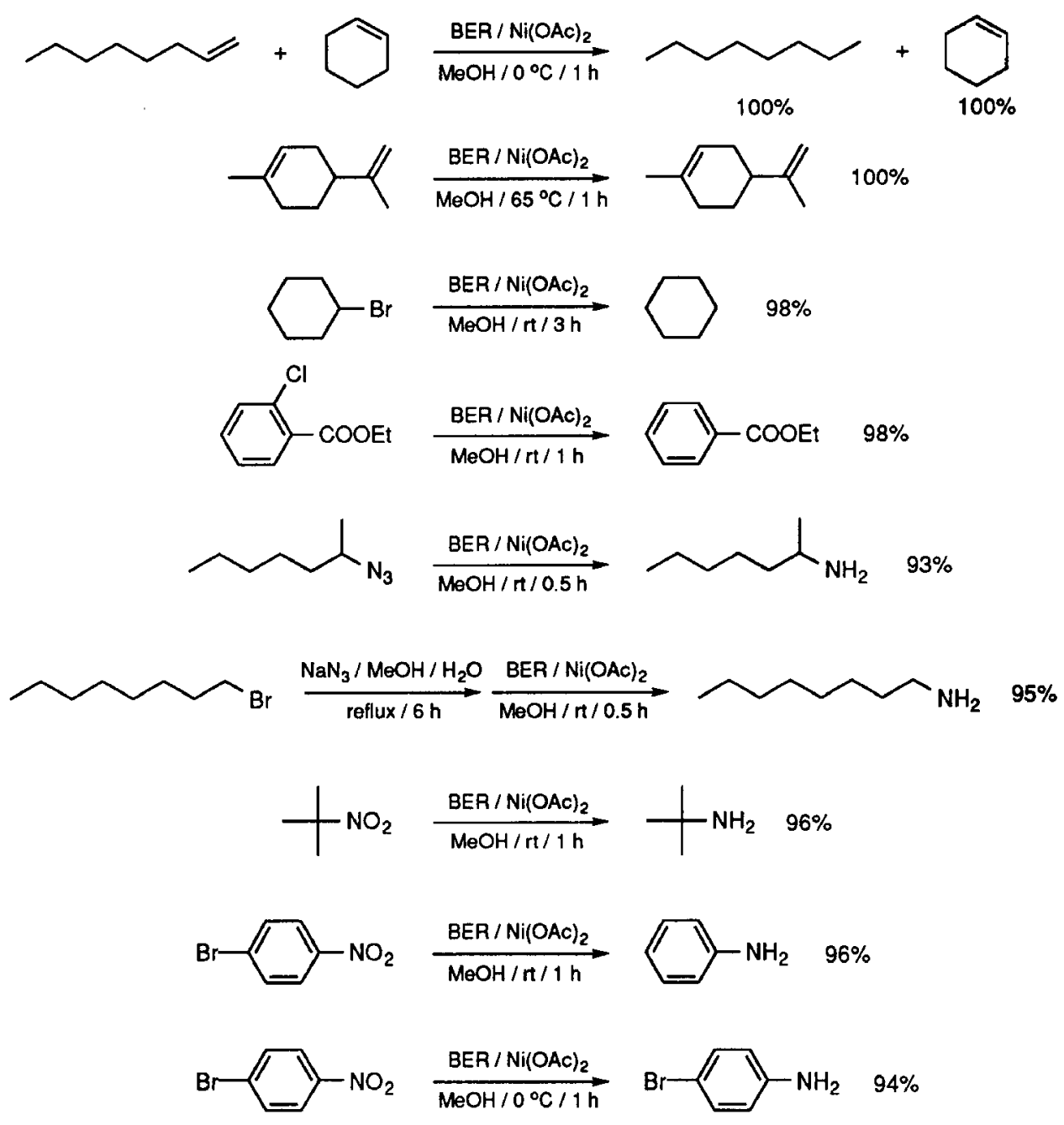

2) BER-Cu in Methanol:

A. Selective Reduction of $\alpha . \beta-$-Unsaturated Carbonyl Compounds and Acid Derivatives: The reduction of $\alpha, \beta$-unsaturated aldehydes and ketones with BER yields exclusively the corresponding allylic alcohols. However, the reduction with BER-Cu yields the corresponding saturated alcohols quantitatively (17). ${ }^{35}$ $\mathrm{NaBH}_{4}$ usually produced the mixture of the two compounds. The presence of $\mathrm{Cu}$ changed the $1,2-$ reduction to 1,4- reduction exclusively. $\alpha, \beta$-Unsaturated acid derivatives were selectively reduced to the corresponding saturated derivatives (18). ${ }^{36}$ This type of selective reduction can be carried out by catalytic hydrogenation and some metal hydrides, but the present system seems to be more selective. It reduces ethyl crotonate in the presence of a terminal olefin, 1-decene, with very good selectivity $(100 / 5)$. 
B. Reduction of Amine N-Oxides: BER-Cu readily reduces both tertiary amine $\mathrm{N}$-oxides and aromatic amine $\mathrm{N}$-oxides. Many reagents have been reported for the reduction, but the present system seems to be an attractive alternative because of its chemoselectivity, excellent yields, and simple work-up procedure $(19 \& 20)^{37}$

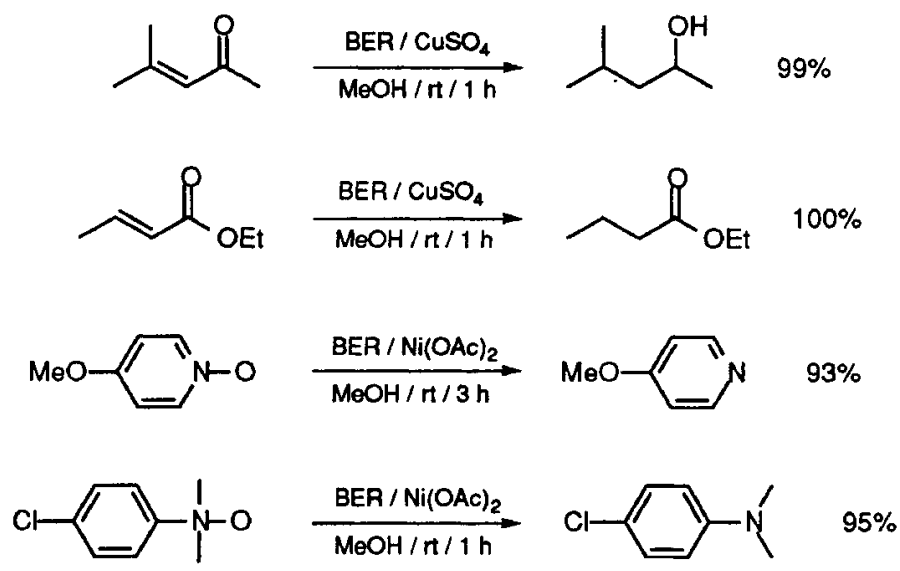

Acknowledgement: Financial support from the Korea Science and Engineering Foundation is gratefully acknowledged.

\section{References and Notes:}

1. H. I. Schlesinger, H. C. Brown, H. R. Hoekstra, and L. R. Rapp, J. Am. Chem. Soc., 75, 199 (1953).

2. A. F. Finholt, A. C. Bond Jr., and H. I. Schlesinger, J. Am. Chem. Soc., 69, 119 (1947).

3. N. G. Gaylord, "Reduction with Complex Hydrides," Interscience Publishers, New York, 1956.

4. H. C. Brown, Tetrahedron, 35, 567 (1979).

5. N. M. Yoon, K. H. Jeong, and D. K. An, Bull. Korean Chem. Soc., 12, 7 (1991).

6. N. M. Yoon and Y. S. Gyoung, J. Org. Chem., 50, 2443 (1985).

7. H. C. Brown and A. Tsukamoto, J. Am. Chem. Soc., 86, 1089 (1964).

8. H. C. Brown, S. C. Kim, and S. Krishnamurthy, J. Org. Chem., 45, 1 (1980).

9. N. M. Yoon, J. H. Ahn, D. K. An, and Y. S. Shon, J. Org. Chem., 58, 1941 (1993).

10. (a) L. I. Zakharkin and I. M. Khorlina, Izv. Akad. Nauk SSSR, Otd. Khim Nauk, 2146 (1959). (b) L. I. Zakharkin and I. M. Khorlina, Dokl. An. SSSR, 116, 422 (1957). (c) M. P. L. Caton, E. C. J.

Coffee, and G. L. Watkins, Tetrahedron Lett., 585 (1974).

11. (a) L. I. Zakharkin and I. M. Khorlina, Tetrahedron Lett., 619 (1962). (b) S. H. Kim, J. H. Kin, and N. M. Yoon, Bull. Korean Chem. Soc., 10, 117 (1989).

12. N. M. Yoon, Y. S. Shon, J. H. Ahn, and J. W. An, Bull. Korean Chem. Soc., 14, 522 (1993).

13. T. B. Sim and N. M. Yoon, Synlett, 827 (1994).

14. H. C. Brown, C. P. Mathew, C. Pyun, J. C. Son, and N. M. Yoon, J. Org. Chem., 49, 3091 (1984).

15. N. M. Yoon, H. S. Yang, and Y. S. Hwang, Bull. Korean Chem. Soc., 8, 285 (1987).

16. N. M. Yoon, Y. S. Hwang, and H. S. Yang, Bull. Korean Chem. Soc., 10, 382 (1989).

17. N. M. Yoon and K. E. Kim, J. Org. Chem., 52, 5564 (1987).

18. (a) H. W. Gibson and F. C. Baily, J. Chem. Soc., Chem. Commun., 815 (1977). (b) M. M. Cook, P.

R. Demko, S. E. Wagner, R. A. Mikulski, and J. G. Clements, Adv. Chem. Ser., 187, 195 (1980). 
19. (a) N. M. Yoon, K. B. Park, and Y. S. Gyoung, Tetrahedron Lett., 5367 (1983). (b) A. R. Sande, M. H. Jagadale, R. B. Mane, and M. M. Salukhe, Tetrahedron Lett., 3501 (1984). (c) N. M. Yoon, Y. S. Gyoung, and D. H. Jeon, Bull. Korean Chem. Soc., 8, 162 (1987).

20. N. M. Yoon, E. G. Kim, H. S. Son, and J. Choi, Synth. Commun., 23, 1595 (1993).

21. R. D. Hutchins and H. Markowitz, J. Org. Chem., 46, 3571 (1981).

22. C. A. Pelter, R. M. Rasser, and S. Mills, J. Chem. Soc. Perkin Trans. I, 717 (1984).

23. N. M. Yoon, J. Choi, and J. H. Ahn, J. Org. Chem., 59, 3490 (1994).

24. B. Ganem and J. O. Osby, Chem. Rev., 86, 763 (1986).

25. C. A. Brown and V. K. Ahuja, J. Org. Chem., 38, 2226 (1973).

26. J. J. Brunet and P. Gallois, J. Org. Chem., 45, 1937 (1980).

27. J. Choi and N. M. Yoon, Manuscript in preparation.

28. S. Krishnamurthy and H. C. Brown, J. Org. Chem., 47, 276 (1982).

29. S. Krishnamurthy and H. C. Brown, J. Org. Chem., 48, 3089 (1983).

30. (a) R. O. Hutchins, D. Kandasamy, F. Dux, C. A. Maryanoff, D. Rotstein, B. Goldsmith, W. Burgoyne, F. Cistone, J. Dalessandro, and J. Puglis, J. Org. Chem., 43, 2259 (1978). (b) R. O. Hutchins, D. Kandasamy, C. A. Maryanoff, D. Masilamani, and B. E. Maryanoff, J. Org. Chem., 42, 3923 (1977).

31. N. M. Yoon, H. J. Lee, J. H. Ahn, and J. Choi, J. Org. Chem., 59, 4687 (1994).

32. N. M. Yoon, J. Choi, and H. J. Lee, Bull. Korean Chem. Soc., 14, 543 (1993).

33. N. M. Yoon, J. Choi, and Y. S. Shon, Synth. Commun., 23, 3047 (1993).

34. N. M. Yoon and J. Choi, Synlett, 135 (1993).

35. N. M. Yoon and T. B. Sim, Bull. Korean Chem. Soc., 14, 749 (1993).

36. T. B. Sim and N. M. Yoon, Synlett in press.

37. T. B. Sim, J. H. Ahn, and N. M. Yoon, Manuscript in prepariation. 